\title{
A comparison of outcomes between immediate and delayed repair of mandibular fractures
}

\author{
Leland Shayne Webb MD1, Sumeet Makhijani MD², Manish Khanna MD³, Mark J Burstein MD", \\ Arthur $\mathrm{N}$ Falk $\mathrm{MD}^{2}$, Dimitri J Koumanis $\mathrm{MD}^{2}$, Jerome D Chao $\mathrm{MD}^{2}$
}

\begin{abstract}
LS Webb, S Makhijani, M Khanna, et al. A comparison of outcomes between immediate and delayed repair of mandibular fractures. Can J Plast Surg 2009;17(4):124-126.

Medical records of patients treated with surgical repair of mandible fractures by the otolaryngology and plastic surgery departments at a level 1 trauma centre were obtained and reviewed. Two study groups were compared: patients treated within $72 \mathrm{~h}$ of the injury and those treated after this time period. Patient demographics, time to repair, fracture types, substance abuse history, etiology, surgical management, complications and length of hospital stay were assessed. The complication rate was $41 \%(n=7)$ within the immediate group and $38 \%(n=6)$ within the delayed group $(P=0.56)$. Complications were prevalent in patients with history of substance abuse in both groups. Complication rates did not increase when repair of mandible fractures was delayed beyond $72 \mathrm{~h}$, while substance abuse was a factor in increasing complications rates. Outpatient triage with elective repair of isolated mandibular fractures appears to be more cost-effective than admission with inpatient management.
\end{abstract}

Key Words: Mandible fracture; Substance abuse

$\mathrm{D}^{\mathrm{s}}$ elays in repairing facial fractures resulting from traumatic injuries are inevitable. They often present with additional systemic injuries that merit more acute considerations, thus rendering repair of the facial fractures as secondary $(1,2)$. Controversy exists in the management of patients with isolated mandible fractures in terms of timing to repair. Many authors advocate immediate repair with open reduction internal fixation (ORIF) and/or maxillo-mandibular fixation (MMF), while others support lag time to repair to allow for a decrease in edema of the surrounding soft tissues $(3,4)$. Regardless, complications from mandible fractures often develop, including infections, hardware exposure, nonunion and jaw pain. Many studies have shown that these complications can often be attributed to many factors including poor patient compliance, substance abuse, and inadequate stabilization or reduction (5-9).

The overall cost is another contributing factor in determining when to operate. This has become an important factor in our current system of managed health care with tighter pressures on reimbursement. A previous study (10) has shown that initial evaluation in the emergency department with subsequent triage and outpatient management appears to be the most cost-effective modality. On the other hand, advantages of immediate inpatient repair include ability to compensate for an unreliable and sometimes uncooperative patient population, as well as the delivery of intravenous antibiotics and oral hygiene.

\section{Comparaison des résultats entre réparation immédiate et retardée des fractures mandibulaires}

Les auteurs ont obtenu et examiné les dossiers médicaux de patients ayant subi une réparation chirurgicale de fracture mandibulaire au département d'otorhinolaryngologie et de chirurgie plastique d'un centre de traumatologie de catégorie 1. Les deux groupes étudiés ont été comparés : patients traités dans les 72 heures suivant le traumatisme ou traités après cette période. Les auteurs ont évalué les caractéristiques démographiques des patients, l'intervalle avant la réparation, les types de fractures, les antécédents de toxicomanie, l'étiologie, l'approche chirurgicale, les complications et la durée de l'hospitalisation. Le taux de complications a été de $41 \%(n=7)$ dans le groupe traité immédiatement et de $38 \%(n=6)$ dans le groupe traité après un délai $(\mathrm{p}=0,56)$. Les complications étaient prévalentes chez les patients qui avaient des antécédents de toxicomanie dans les deux groupes. Les taux de complications n'ont pas augmenté lorsque la réparation des fractures mandibulaires s'effectuait au-delà de 72 heures après le traumatisme, tandis que la consommation de substances a représenté un facteur dans l'augmentation des taux de complications. Le triage en externe des patients devant subir une réparation élective de fracture mandibulaire isolée semble plus économique que leur admission avec traitement durant l'hospitalisation.

The present study assesses the outcomes of immediate versus delayed repair of isolated mandible fractures in a single institution as comparatively carried out by the Division of Otolaryngology and Division of Plastic and Reconstructive Surgery at Albany Medical Center (Albany, New York). The final outcomes that will be mostly closely evaluated are the number of complications relative to the timing of operation as well as the correlation of these complications with substance abuse.

\section{METHODS}

Records of patients who presented to Albany Medical Center with facial fractures over a two-year period between 2003 and 2005 were retrospectively reveiwed. The evaluation and management of patients who suffer from facial trauma is equally divided on a rotating weekly schedule between the Division of Otolaryngology Head and Neck Surgery and the Division of Plastic and Reconstructive Surgery. Exclusion criteria for the study included patients with incomplete records and those with pan-facial fractures including LeFort and naso-orbital-ethmoid fractures. This allowed evaluation of all isolated mandible fractures over the study period.

The treatment algorithm for mandible fractures differs between the two divisions. The Plastic and Reconstructive Surgery service routinely admits mandible fracture patients from the emergency department and plans for operative treatment as soon as possible if the patient is cleared medically. The

${ }^{1}$ Hunstad Center, Charlotte, North Carolina; ${ }^{2}$ Albany Medical Center, Albany, New York; ${ }^{3}$ Private practice, Palo Alto, California; ${ }^{4}$ Private practice, Philadelphia, Pennsylvania, USA

Correspondence: Dr Sumeet N Makhijani, 43 New Scotland Avenue, Albany, New York 12208, USA. Telephone 518-262-2229,

e-mailmakhijs@gmail.com 
TABLE 1

Patient demographics, mechanism of injury and fracture type

\begin{tabular}{|c|c|c|c|c|c|c|}
\hline Group & $\mathbf{n}$ & $\begin{array}{c}\text { Age, } \\
\text { mean years }\end{array}$ & $\begin{array}{c}\text { Sex } \\
\text { (male:female) }\end{array}$ & Mechanism of injury & $\begin{array}{c}\text { Number of } \\
\text { fractures }\end{array}$ & $\begin{array}{l}\text { Location of fracture } \\
\text { (most common) }\end{array}$ \\
\hline Immediate & 17 & 29.2 & $13: 4$ & $\begin{array}{l}\text { Assault: } \mathrm{n}=8 \\
\text { MVA: } \mathrm{n}=5 \\
\text { Accident: } \mathrm{n}=4\end{array}$ & 29 & $\begin{array}{l}\text { Parasymphyseal: } \mathrm{n}=12 \\
\text { Angle: } \mathrm{n}=6 \\
\text { Subcondylar: } \mathrm{n}=4\end{array}$ \\
\hline Delayed & 16 & 24.8 & 11:5 & $\begin{array}{l}\text { Assault: } n=7 \\
\text { MVA: } n=5 \\
\text { Accident: } n=3 \\
\text { Dental: } n=1\end{array}$ & 23 & $\begin{array}{l}\text { Parasymphyseal: } n=6 \\
\text { Angle: } n=5 \\
\text { Subcondylar: } n=5\end{array}$ \\
\hline
\end{tabular}

Delayed Patients treated at least $72 \mathrm{~h}$ after injury; Immediate Patients treated within $72 \mathrm{~h}$ of injury; MVA Motor vehicle accident

Otolaryngology service advocates initial evaluation in the emergency room with subsequent referral to the outpatient clinic within a few days to schedule elective repair shortly thereafter. All patients are treated with antibiotics, pain medication and chlorhexidine oral rinse. Operative techniques are similar between both services including MMF, via placement of arch bars or MMF screws, and/or ORIF based on AO/ASIF guidelines.

Patient demographics, etiology, fracture types, lag time to repair, substance use, operative repair techniques, complications, length of admission and time in MMF were collected for both groups. Complications noted in the present study included temporomandibular joint pain, hardware exposure, trismus, malocclusion and nonunion. The length of admission calculation was determined for patients who were in the hospital for treatment of their mandible injuries only. Those with prolonged inpatient hospital courses due to other traumatic injuries were excluded from the length of admission tabulations.

\section{RESULTS}

Thirty-three patients qualified for the present retrospective study based on exclusion criteria. Seventeen patients were repaired within $72 \mathrm{~h}$ of the injury (immediate group) while the remaining 16 were repaired after $72 \mathrm{~h}$ of the inciting event (delayed group). There were a total of 24 males and nine females in the study group with a mean age of 29.2 years (range 15 to 61 years) in the immediate group and 24.8 years (range 15 to 39 years) in the delayed group. The most common fracture types in both groups were parasymphyseal and angle fractures with assault as the most common etiology (Table 1). Mean time to repair for the immediate group was one day (range one to three days) versus 8.8 days (range four to 27 days) for the delayed group. All patients in the immediate group underwent MMF (four with arch bars) and 10 underwent ORIF also. Fourteen patients in the delayed group underwent MMF (four with arch bars) and 12 also underwent ORIF. The mean length of time in MMF for the delayed group was five weeks (range three to eight weeks) and 4.5 weeks (range two to eight weeks) for the delayed group.

In the immediate group, seven of the 17 patients reported either isolated or combined use of alcohol, tobacco or illicit drugs. Six patients denied use of any of these substances, while four patients had undocumented substance abuse. In the delayed group, 10 of the 16 patients reported either isolated or combined use of alcohol, tobacco or illicit drugs, while six patients reported not using any substances. One patient in the delayed group had a history of previous mandibular trauma, while one patient in the immediate group was in her first trimester of pregnancy.
TABLE 2

Comparison of major and minor complications between the immediate and delayed group

\begin{tabular}{lccc}
\hline Group & Major & Minor & Total \\
\hline Immediate & 1 & 6 & 7 \\
Delayed & 2 & 4 & 6 \\
\hline
\end{tabular}

Delayed Patients treated at least $72 \mathrm{~h}$ after injury; Immediate Patients treated within 72 h of injury

The complication rate was $41 \%(n=7)$ within the immediate group and $38 \%(n=6)$ for the delayed group. This was not statistically significant using a Fisher's exact test $(\mathrm{P}=0.56)$. In the immediate group, there were three patients with temporomandibular joint pain after surgery, one patient with an exposed plate that required removal, one patient with trismus and two patients with malocclusion. One patient underwent revision surgery for severe malocclusion. In the delayed group, one patient had temporomandibular joint pain after surgery, two patients required removal of exposed plates with one of these patients developing nonunion requiring revision surgery. Two patients had persistent malocclusion and were referred to oral surgery for further management. A major complication was defined as one that required either readmission or reoperation. All other complications were considered minor in nature (Table 2). Four of the seven patients $(57 \%)$ with complications in the immediate group had a history of substance use/abuse versus four of six patients $(66 \%)$ with complications in the delayed group. This was not statistically significant using a Fisher's exact test $(\mathrm{P}=0.82)$.

For patients who suffered isolated facial fractures, 11 patients in the immediate group had an average hospital course of three days, while three patients in the delayed group stayed an average of one day in the hospital and nine were discharged on the day of the operation.

\section{DISCUSSION}

Intuitively it would reason that a delay in the treatment of mandible fractures would lead to a higher complication rate. Indeed, earlier studies have shown a correlation between earlier treatment and decreased morbidity. Anderson and Alpert (11) displayed a 16\% overall postoperative infection rate in a study of 75 mandible fractures, but no infections occurred in patients operated on within $24 \mathrm{~h}$ of injury. Another study by Maloney et al (12) reviewed 204 fractures in 131 patients with an overall infection rate of $4.4 \%$. However, compliant patients treated within $72 \mathrm{~h}$ of injury had no infections (12). 
Our results suggest that a treatment delay in patients with isolated mandible fractures is not associated with a higher complication risk. In our study of patients treated within three days of injury versus patients treated after three days, the complication rates were $41 \%$ and $38 \%$, respectively. This small difference was not statistically significant $(\mathrm{P}=0.56)$. These results have been demonstrated in previous studies $(4,5,11,13,14)$.

While lag time to repair did not appear to correlate with an increased complication rate, substance use did appear to be associated. Passeri et al (9) report $64 \%$ of patients in their study had a history of chronic alcohol or drug abuse, with a postsurgical complication rate for chronic alcohol abuse, nonintravenous drug use and intravenous drug use of $15.5 \%, 19.2 \%$ and $30 \%$, respectively. On the other hand, patients who did not report any substance abuse had a $6.2 \%$ complication rate (9). Billar et al (13) reported only $34.5 \%$ of their patients were substance free. All patients with infectious complications and one-half of the patients with technical complications were substance abusers. Our study also supports an increase in complication risk in patients with substance use/abuse. When comparing nonsubstance abusers with those using alcohol, tobacco or illicit drugs, a large proportion of the latter group developed complications. The rate of complications due to substance abuse in the immediate group was $57 \%$, while in the delayed group, it was $66 \%$.

Another important consideration in managing patients with a mandible fracture is determining a cost-effective

\section{REFERENCES}

1. Kaufman MS, Marciani RD, Thomson SF, Hines WP. Treatment of facial fractures in neurologically injured patients. J Oral Maxillofac Surg 1984;42:250-2.

2. Derdyn C, Persing JA, Broaddus WC, et al. Craniofacial trauma: An assessment of risk related to timing of surgery. Plast Reconstr Surg 1990;86:238-45; discussion 246-7.

3. Maloney PL, Lincoln RE, Coyne CP. A protocol for the management of compound mandibular fractures based on the time from injury to treatment. J Oral Maxillofac Surg 2001;59:879-84; discussion 885-6.

4. Stone IE, Dodson TB, Bays RA. Risk factors for infection following operative treatment of mandibular fractures: A multivariate analysis. Plast Reconstr Surg 1993;91:64-8.

5. Furr AM, Schweinfurth JM, May WL. Factors associated with longterm complications after repair of mandibular fractures. Laryngoscope 2006;116:427-30.

6. Li Z, Zhang W, Li ZB, Li JR. Abnormal union of mandibular fractures: A review of 84 cases. J Oral Maxillofac Surg 2006;64:1225-31.

7. Marciani RD, Haley JV, Kohn MW. Patient compliance - a factor in facial trauma repair. Oral Surg Oral Med Oral Pathol 1990;70:428-30. treatment algorithm. Stable patients with mandible fractures who can tolerate oral intake and who display no airway compromise can be managed as outpatients and scheduled as elective cases. Patients admitted from the emergency department for immediate repair were often postponed due to operating room delays for lack of personnel or more acute cases taking priority. This leads to more prolonged hospital admissions and increased costs (10). Elective repair allows for a shorter hospital admission as well as use of ambulatory surgical facilities, which can be more cost-effective than performing surgery at a tertiary care centre.

There are several shortcomings of the present study. The retrospective nature of this study is one limitation. In our chart review, important data including substance use history and operative details were not always available and excluded a significant number of patients from the study. We hope this initial study can launch a prospective study that measures similar parameters in these patient groups. In addition, if our study reported actual monetary costs between patients operated on as an inpatient versus those treated as an outpatient, it would lend further credence to our presumption that a delay in treatment is cost-effective.

POLICY ISSUES: This manuscript is an original contribution not previously published except as an abstract at the Senior Resident's Conference in Washington, DC, in January 2007. There are no conflicts of interest, and this study was approved by the Albany Medical Center Institutional Review Board.

8. Mathog RH, Toma V, Clayman L, Wolf S. Nonunion of the mandible: An analysis of contributing factors. J Oral Maxillofac Surg 2000;58:746-52; discussion 752-3.

9. Passeri LA, Ellis E 3rd, Sinn DP. Relationship of substance abuse to complications with mandibular fractures. J Oral Maxillofac Surg 1993;51:22-5.

10. David LR, Bisseck M, Defranzo A, et al. Cost-based analysis of the treatment of mandibular fractures in a tertiary care center. J Trauma 2003;55:514-7.

11. Anderson T, Alpert B. Experience with rigid fixation of mandibular fractures and immediate function. J Oral Maxillofac Surg 1992;50:555-60; discussion 560-1.

12. Maloney PL, Welch TB, Doku HC. Early immobilization of mandibular fractures: A retrospective study. J Oral Maxillofac Surg 1991;49:698-702; discussion 702-3.

13. Biller JA, Pletcher SD, Goldberg AN, Murr AH. Complications and the time to repair of mandible fractures. Laryngoscope 2005;115:769-72.

14. Lamphier J, Ziccardi V, Ruvo A, Janel M. Complications of mandibular fractures in an urban teaching center. J Oral Maxillofac Surg 2003;61:745-9; discussion 749-50. 